\title{
PRELIMINARY RESULTS TESTING WHAT DIFFERENT DESIGN SOLUTIONS ARISE FROM DIFFERENT SUSTAINABLE DESIGN METHODS
}

\author{
Faludi, Jeremy (1); Ali, Omar (2); Srour, Ola (2); Mecanna, Selim (2); Kamareddine, Rami (3); \\ Chatty, Tejaswini (1)
}

1: Dartmouth College; 2: American University of Beirut; 3: University of Balamand

\begin{abstract}
Do different sustainable design methods generate different sustainable design ideas? Do they also drive different product innovation ideas? This project empirically tested three design methods: The Natural Step, Whole System Mapping, and Biomimicry. Testing involved qualitatively categorizing 1,115 design ideas from 23 workshops for over 30 companies, including consultancies and manufacturers in consumer electronics, furniture, and apparel. The categorized ideas were then counted to determine if the different design methods caused different kinds of ideas. They did. For example, The Natural Step drove more ideas on green material choice, circular end of life, and social impacts, while Biomimicry drove more durability ideas and Whole System Mapping drove more cost reduction ideas, among other differences. Overall, The Natural Step generated the highest percentage of sustainability ideas, Biomimicry generated the most innovation ideas, and Whole System Mapping generated a balance of both. These preliminary results should help designers and engineers choose design methods suited to the types of design solutions they desire.
\end{abstract}

Keywords: Design methods, Sustainability, Innovation, Circular economy

\section{Contact:}

Faludi, Jeremy

Dartmouth College

Engineering

United States of America

jeremy.faludi@dartmouth.edu

Cite this article: Faludi, J., Ali, O., Srour, O., Mecanna, S., Kamareddine, R., Chatty, T. (2019) 'Preliminary Results Testing What Different Design Solutions Arise from Different Sustainable Design Methods', in Proceedings of the 22nd International Conference on Engineering Design (ICED19), Delft, The Netherlands, 5-8 August 2019. DOI:10.1017/ dsi.2019.342 


\section{INTRODUCTION}

A nail can be pounded with a screwdriver, but a hammer is a better tool for the job. Many sustainable design tools and methods exist, from measuring impacts to generating innovation to setting goals and more; some perform multiple functions. Even for "traditional" design methods, "There are neither good nor bad methods, but only methods that are more or less effective under particular circumstances" (Homans, 1949). Some reasons to use different sustainable design methods include timing in the design process (Telenko et al., 2016), (Ramani et al., 2010); applicability to product life-cycle stages or sustainability strategies (White et al., 2013), (Oehlberg et al., 2012); whether they are qualitative or quantitative (Sheldrick and Rahimifard, 2013), (Ramani et al., 2010), (Shedroff, 2009); whether they consider environmental, social, and/or economic factors (Shedroff, 2009), (Brink et al., 2009); whether they are methods, guidelines, checklists, or analytic tools (Knight and Jenkins, 2009); or "actionable" versus "visionary" and "selective" versus "integrated" (Brink et al., 2009).

Such recommendations are nearly all theoretical, categorizing the methods' activities or mindsets, not empirical results of using the methods. To support sustainable innovators with specific agendas, this study empirically examines the kinds of design ideas generated by different design methods. Some studies have interviewed or surveyed practitioners about eco-design methods increasing their general environmental consideration (Deutz et al., 2013) or social consideration (Tromp and Hekkert, 2016), but self-reporting is not always reliable. Almost no studies examine the actual ideas produced by different sustainable design methods. One study that did examine ideas produced, comparing eco-design to "traditional" design, found outcomes depended more on the designers than the tools (Vallet et al., 2013). More research is required to support design teams seeking specific outcomes. Many more empirical studies have been performed of traditional design method outcomes, especially attempts to quantify innovation / creativity driven by design activities (Shah et al., 2003), (Sarkar and Chakrabarti, 2011), (Oman et al., 2013), (Häggman et al., 2015), (Yilmaz et al., 2016). The most famous metrics may be Shah's "variety", "novelty", "quantity", and "quality" (Shah et al., 2003). Some have found that introducing sustainability considerations hurts creativity (Collado-Ruiz and Ghorabi, 2010), but some green design methods, such as Biomimicry, have been empirically shown to enhance innovation (Vandevenne et al., 2016).

To help practitioners choose sustainable design methods supporting their desired outcomes, this paper presents preliminary results of empirically testing three sustainable design methods for differences in the design ideas they produced. It counted design ideas of different kinds emerging from professionals using each design method; specifically, it counted kinds of sustainability benefits and kinds of product innovation. It intentionally avoided hypothesizing what methods would produce what outcomes, to avoid biasing qualitative interpretations of results. This may help choose the best design method for a job, like a screwdriver versus a hammer, without needing to trust theoretical analyses or claims of design method creators.

\section{METHODS}

\subsection{Design methods analysed}

This project compared three sustainable design methods: The Natural Step (Robèrt, 1991), (Baxter et al., 2009), Whole System Mapping (Faludi, 2015), and Biomimicry (Benyus, 1997), (Baumeister et al., 2013). Note that The Natural Step was created for sustainable business strategy, and has now been superseded by Framework for Strategic Sustainable Development (FSSD) (Broman and Robèrt, 2017), but the method has also been used by designers in industry for over a decade, and is still often referred to by the old name. These three were chosen based on recommendations by 27 professional designers, engineers, and managers in product development (Faludi and Agogino, 2018) and because they have different approaches. The professionals were not given lists to choose from, but asked for recommendations from their experience of what drives sustainability and innovation; the professionals spanned a variety of firms, both manufacturers and consultancies in consumer products, electronics, apparel, furniture, telecom, and more (see citation for details). A summary of the methods follows: 
1. The Natural Step defines a vision for perfect environmental and social sustainability, the four System Conditions (Baxter et al., 2009). It then uses "backcasting" to set those conditions as the goal, identify the gap between that and the present, ideate new possibilities to bridge the gap, and choose what to act on. The choices are based on ideas' adherence to the vision, their return on investment (economic or sustainability impact), and their ability to drive further progress.

2. Whole System Mapping is a four-step method (Faludi, 2015); first, a visual map of the product's whole system is drawn collaboratively. Second, life cycle assessment estimation and business concerns are used to set priorities. Third, brainstorming occurs on the system map, to ensure new ideas for every part of the system and to drive radical innovation by eliminating system nodes. Fourth, winning ideas are chosen based on step two's priorities.

3. Biomimicry is practiced in diverse ways, but was taught in the following way (Faludi and Menter, 2013): First, the design problem is redefined biologically, then biological models are found, both through examining physical samples and online via AskNature.org. These biological strategies are translated to manufacturable products by a brainstorming step. Finally, these ideas are tested for compatibility with nature by comparing to the Biomimicry Institute's list of "Nature's Principles" (Baumeister et al., 2013). These principles are also used to brainstorm new solutions.

\subsection{Participant demographics}

Data was collected from 23 workshops for professionals performing green redesigns of actual products in consumer electronics, apparel, furniture, and other industries. The participants were professional designers, engineers, and managers / executives from over 30 companies (see Table 1). Many participated in more than one workshop. Participants were not the unit of analysis here, but this data was a subset of a larger study (Faludi, 2017a) where demographic data was collected in surveys. Some participants did not fill out surveys; they are listed as "anonymous". Often their company type and size could be determined without their surveys, but sometimes these also had to be listed as "anonymous".

\begin{tabular}{|c|c|c|c|c|c|c|c|c|}
\hline \multirow{2}{*}{$\begin{array}{l}\text { Design } \\
\text { Method }\end{array}$} & \multirow{2}{*}{$\begin{array}{l}\text { Total } \\
\text { Partic. }\end{array}$} & \multicolumn{2}{|c|}{$\begin{array}{l}\text { Company } \\
\text { Type }\end{array}$} & \multicolumn{2}{|l|}{ Size } & \multicolumn{2}{|c|}{$\begin{array}{l}\text { Workshop } \\
\text { Duration }\end{array}$} & \multirow[t]{2}{*}{ Industry } \\
\hline & & Mfr & Cons. & Smal & Large & 2 & $4 \mathrm{hr}$ & \\
\hline $\begin{array}{l}\text { The Natural } \\
\text { Step }\end{array}$ & 71 & 67 & 4 & 32 & 39 & 9 & 62 & $\begin{array}{l}\text { Cons.Elec.: } 7 \text { Apparel: } \\
26 \\
\text { Furniture: } 0 \text { Other: } 14\end{array}$ \\
\hline $\begin{array}{l}\text { Whole } \\
\text { System } \\
\text { Mapping } \\
\end{array}$ & 104 & 37 & $\begin{array}{r}36 \\
31\end{array}$ & 31 & $\begin{array}{r}42 \\
31\end{array}$ & 72 & 32 & $\begin{array}{c}\text { Cons.Elec.: } 35 \\
\text { Apparel: } 7 \\
\text { Furniture: } 21 \quad \text { Other: } 10\end{array}$ \\
\hline Biomimicry & 79 & 40 & 39 & 39 & 40 & 63 & 16 & $\begin{array}{c}\text { Cons.Elec.: } 39 \text { Apparel: } \\
16 \\
\text { Furniture: } 0 \text { Other: } 24 \\
\end{array}$ \\
\hline
\end{tabular}

Table 1. Demographics by company; "Partic" = participants, "Mfr" = manufacturers, "Cons" = product development consultancy, "Cons. Elec." = consumer electronics.

\subsection{Data collection and analysis}

The workshops resulted in 1,115 design ideas, in the form of writing or drawings on Post-it notes; each workshop focused on a different product in development by each company. While counting ideas does not measure "good" ideas, "good" is highly subjective. In the interests of objectivity, this study used quantity of ideas as a metric of effectiveness, as other studies have (Shah, Smith and Vargas- Hernandez, 2003). Some Post-its held multiple ideas, some ideas spanned more than one Post-it. 298 ideas were generated in The Natural Step, 460 in Whole System Mapping, and 337 in Biomimicry; however, since there were different numbers of workshops for different numbers of participants, all results were normalized into percentage of total ideas from each design method. Photographs of the Post-its were coded and counted using MaxQDA software. Since some workshops included participants from several demographics (company sizes, types, and industries), design ideas could not be separated by demographic without substantially reducing sample size. Each design idea was coded by type of sustainability strategy and 
product innovation strategy. Four students working in pairs coded all ideas separately; intercoder agreement Cohen's Kappa of .90 was achieved. See Figure 1. There were some disagreements, however; in the case of the "waterless dyeing" idea in that figure, one pair only coded its sustainability improvement as "Mfg - Cleaner Process", while the other tagged it as that plus "Energy - Use Reduction".

For sustainability strategy, each idea was coded on the aspect of the product life-cycle it could improve: materials and manufacturing (including waste reduction, material choice, material use reduction, and cleaner manufacturing processes), transportation (including transport reduction and cleaner transport modes), energy use (including use reduction and cleaner energy sources), more service per unit material (including product service systems / sharing, durability / long life, and repair / upgrade), end of life (including recycling / reuse and composting), social benefits (including labour benefits and other benefits), and changing user behaviour for a more sustainable lifestyle. Ideas were coded as "other" if they did provide a likely sustainability benefit but did not easily fall into the above categories. Ideas were coded as "unclear" if it was uncertain whether they provided sustainability benefit or not, and "unreadable" if the ideas were indecipherable text or drawings. The researchers coding were not present at the design workshops and had no video or other recordings to help interpret Post-its, so $11-14 \%$ of all ideas were lost in translation.

For product innovation strategy, each idea was coded on how it could improve business value even if sustainability is assumed to have no value (e.g., the idea "reduce fabric waste" would not count because the end product would be similar). These categories were based on the common ground among several prominent experts on creativity and innovation; they included quality and novelty from Shah et al. (Shah, Smith and Vargas-Hernandez, 2003) and Oman et al. (Oman et al., 2013), attractiveness and technical quality from Christiaans (Christiaans, 2002), profit model and product performance from Keeley et al. (Keeley et al., 2013), usefulness from Sarkar and Chakrabarti (Sarkar and Chakrabarti, 2011), and recommendations from the 27 professionals mentioned earlier. The categories were combined into quality (judged by improved features, interface, or robustness), marketability (judged by novelty or desirability not related to quality), and profit (judged by reducing costs or increasing revenue). Ideas were coded as "unclear" if it was uncertain whether they provided innovation benefit, and "unreadable" if the ideas were indecipherable.

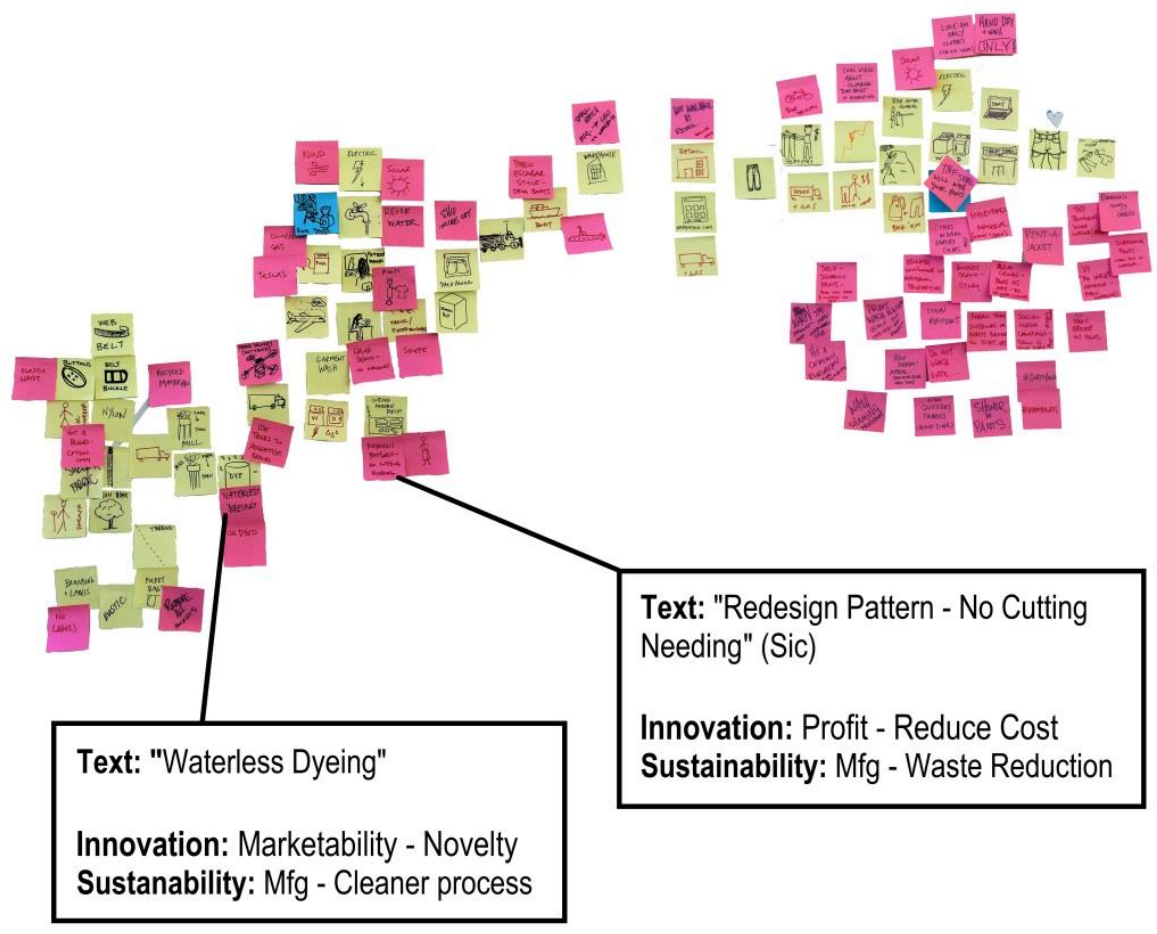

Figure 1. Workshop Post-its, showing two design ideas coded by sustainability strategy and product quality innovation. Note that in this photo from Whole System Mapping, only pink and blue Post-its are new design ideas; yellow Post-its are system map components. 


\section{RESULTS}

\subsection{Sustainability strategy differences}

The three different design methods resulted in design ideas with substantially different sustainability benefits. Figure 2 depicts the top-level categories, Figure 3 shows breakdowns by subcategory.

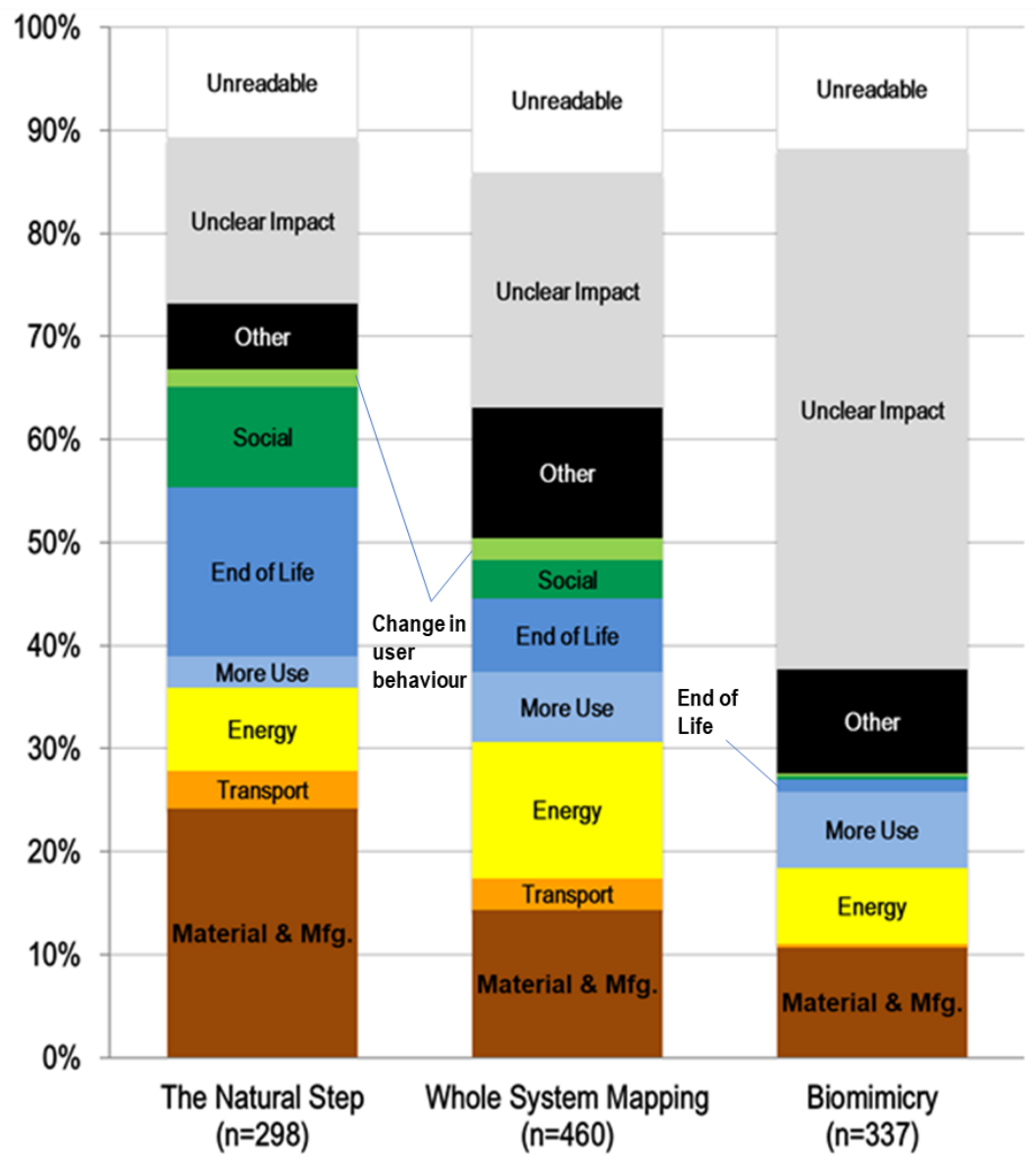

Figure 2. Different design ideas resulting from different design methods categorized by toplevel sustainability benefit; $n=$ number of coded ideas in all workshops for each method.

Figure 2 shows that The Natural Step generated a higher percentage of material and manufacturing ideas than the average of Whole System Mapping and Biomimicry $(p=.004$; hereafter, all p-value comparisons are between one method and the average of the other two, unless otherwise stated). Examples of these ideas from The Natural Step included "use natural/no dyes" and "organic flax"; from Whole System Mapping, "lightweighting" and "molded-in buttons"; from Biomimicry, "materials: micro-fluidics" and "Joshua trees tubular struts". The Natural Step's advantage here likely comes from explicitly describing zero mining in its Four System Conditions. Biomimicry had the least percentage in this area $(\mathrm{p}=.02)$. The Natural Step and Whole System Mapping generated more transport ideas than Biomimicry ( $\mathrm{p}=.04$; for example, "co-locate suppliers, reduce transport"); this is likely from their explicit mentions of supply chains, which Biomimicry lacked. Whole System Mapping may appear to have generated more energy ideas than the other two methods, but the difference was not statistically significant.

The Natural Step generated a significantly greater percentage of end of life ideas than the average of the other two methods $(\mathrm{p}=.0002$; for example, "recycle all waste", "biodegradable packaging and tags"), while Biomimicry had the least $(\mathrm{p}=3 \times 10-5)$. Similarly, for social impacts, The Natural Step generated significantly more ideas $(p=.003$; for example, "fair trade for all", "accelerating universal nutrition"), while Biomimicry generated only one. This concurs with theoretical analyses (Brink et al., 2009), (Shedroff, 2009) and is likely because The Natural Step's 
vision for sustainability explicitly names social factors, while Whole System Mapping and Biomimicry as taught did not. However, Whole System Mapping also does not explicitly name social factors, but still generated many such ideas; its social awareness may stem from the user and supply chain appearing in the system map. Some of its social benefits were user benefits (e.g., "provides privacy"), but many were not ("sail becomes walls to house homeless"). For behaviour change, none of the three methods generated many ideas: Biomimicry generated one, The Natural Step five, and Whole System Mapping ten.

Overall, The Natural Step generated the highest percentage of sustainability benefit ideas $(\mathrm{p}=$ $3 \times 10-6$ ), presumably because it was the most prescriptive in sustainability goals. Biomimicry generated the least (50\% of The Natural Step and 60\% of Whole System Mapping). This may be because it has less clear metrics for sustainability than the other two methods. As one participant said in a post-workshop survey, "you could create a solution that is Biomimicry that is incredibly effective but could be incredibly toxic to the environment to make."

Figure 3 shows the sustainability categorizations broken down into finer subcategories.

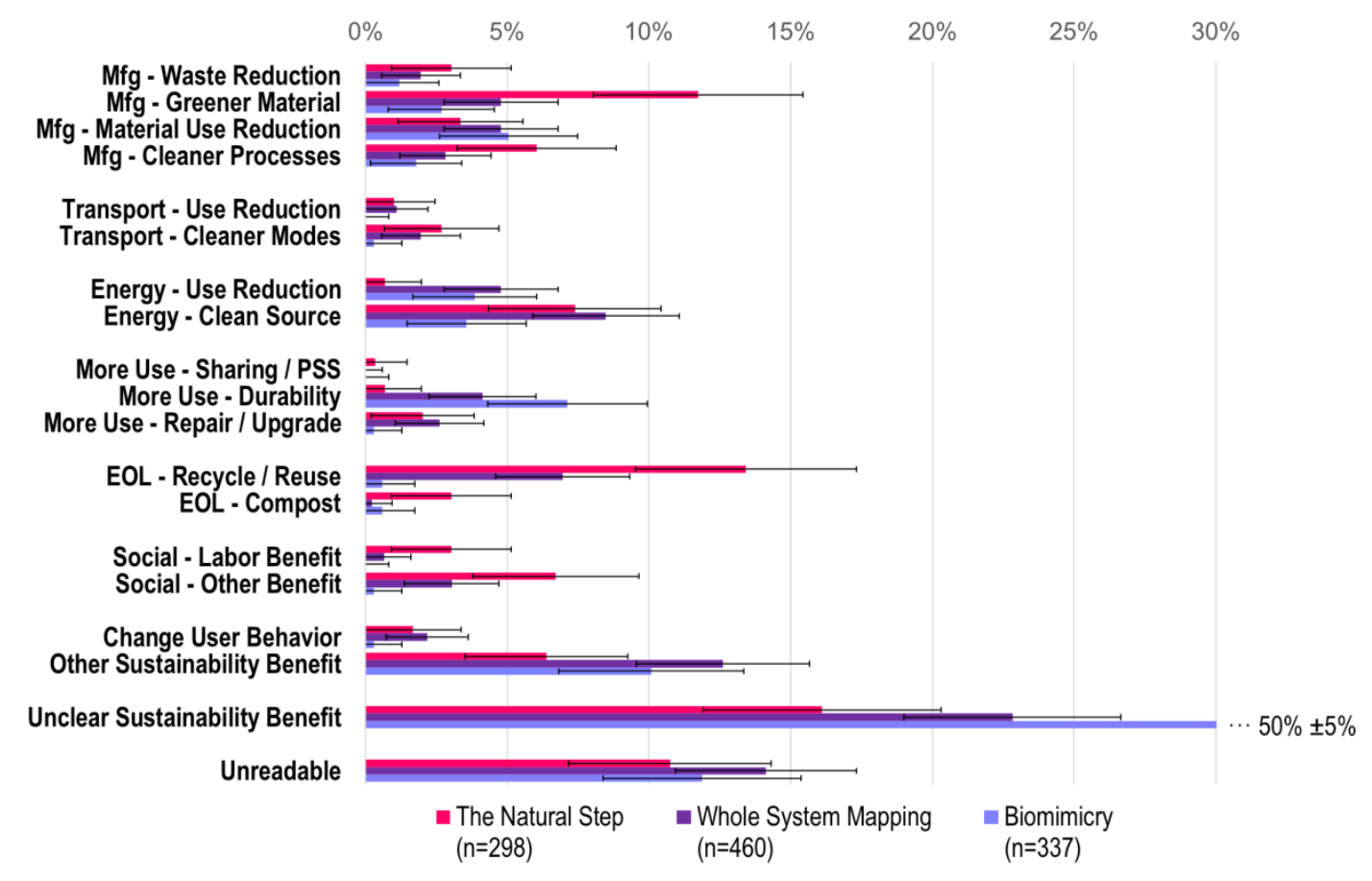

Figure 3. Sustainability results by subcategory; $n=$ number of ideas in all workshops. "PSS" = product service system.

Figure 3 shows that when dividing material and manufacturing into subcategories, the percentages of ideas from the three methods are similar for each subcategory, except for Green Materials, where The Natural Step lead strongly $(\mathrm{p}=.007)$. This caused most of its advantage for the overall category in Figure 2. Transportation remained similar across all design methods when broken down into use reduction and clean transport. When energy was broken down into use reduction and clean sources, The Natural Step had few energy use reduction ideas $(p=.04)$. Breaking down service ("more use"), Biomimicry generated many durability ideas (for example, "internal support structure", "calcium shell structure doesn't allow water in"), while The Natural Step had the least $(\mathrm{p}=.009)$. Breaking down end of life, The Natural Step and Whole System Mapping's advantages were mostly due to their recycling / reuse ideas, e.g. "reusable food equipment", "allow 100\% regrind". Breaking down social impacts, most of The Natural Step and Whole System Mapping's benefits were not labour, though there were several of those (e.g., "fair trade for all", "mill/vendor working conditions - wage, sanitation, green energy"); most were "other" benefits (quoted earlier).

Exploring Figure 3's subcategories within each design method, in materials \& manufacturing, The Natural Step had significantly more ideas for greener materials than waste reduction or material use reduction; neither Biomimicry nor Whole System Mapping showed such a trend. For energy, The Natural Step also had significantly more ideas for clean energy source than for energy use reduction, while the other two design methods lacked such a trend. For service ("more 
use"), Biomimicry produced more durability ideas than sharing / product-service system or repair / upgrade, while the other design methods lacked a strong trend, except sharing / product-service system did not receive many ideas from any of the three design methods. For end of life, The Natural Step and Whole System Mapping had significantly more ideas for recycle / reuse than composting.

\subsection{Innovation strategy differences}

The three different design methods resulted in different innovation benefits; as with sustainability, some of these differences were expected, others were surprises. Figure 4 shows how the different design methods suggested different kinds of innovations in product quality, marketability, profitability, or other business benefits.

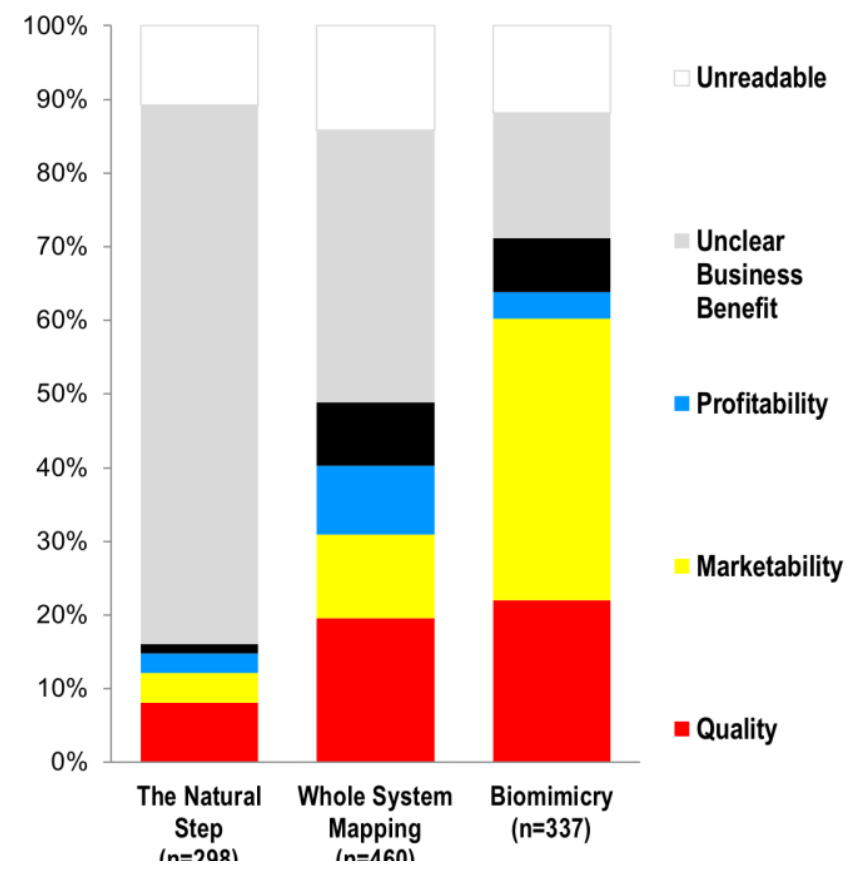

Figure 4. Design ideas categorized by their impact on Product Innovation.

Figure 4 shows that overall, Biomimicry generated the most product innovation ideas $(\mathrm{p}=4 \mathrm{x} 10-17$ for the sum of all ideas excluding "unclear" and "unreadable"). This may be due to it containing more research and ideation activities than the other methods (Faludi, 2017b). Biomimicry's primary advantage was generating far more marketability-related ideas than the average of the other two design methods ( $\mathrm{p}=8 \times 10-14)$, e.g., "incorporate diversity through multiple options on same line". It and Whole System Mapping generated a similar percentage of product quality ideas. Whole System Mapping generated more profitability ideas $(p=.009)$, e.g., "optimize assy, lower cost" and "smaller PCB". The Natural Step generated far fewer product innovation ideas: roughly $1 / 3$ that of Whole System Mapping and 1/4 that of Biomimicry; this included fewer ideas in quality $(\mathrm{p}=4 \times 10-4)$, marketability $(\mathrm{p}=4 \times 10-10)$, and "other" $(\mathrm{p}=.003)$. Examples of The Natural Step's ideas for sustainability but not innovation include "localize production" and "reduce fabric waste". Its lack of product innovation ideas are likely because of its focus on business strategy rather than product features.

Figure 5 displays a detailed breakdown of the subcategories and their differences. 


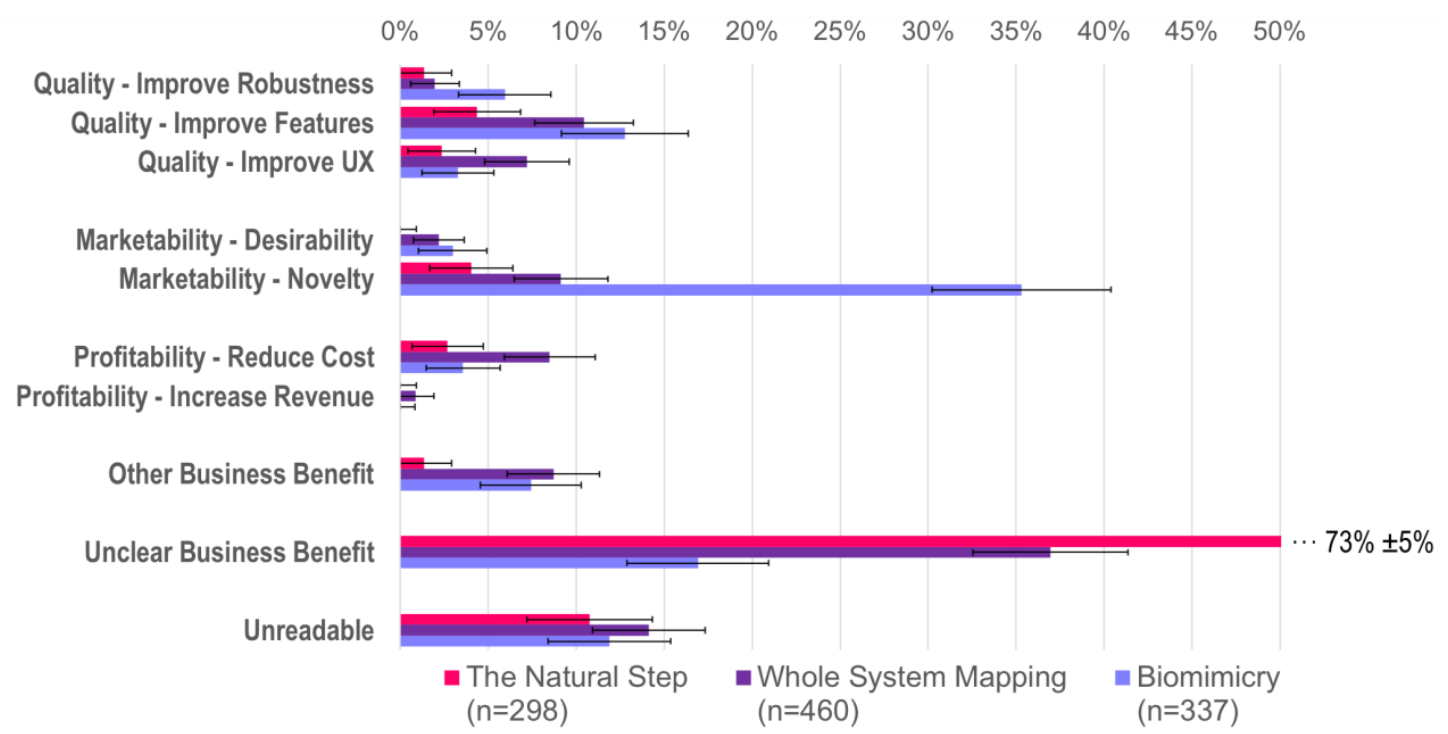

Figure 5. Product Innovation results by subcategory; "UX" = user experience.

Figure 5 shows that within product quality ideas, Biomimicry generated a higher percentage of ideas to improve product robustness than the other two methods $(\mathrm{p}=.04$; examples quoted above under "durability"). Whole System Mapping generated more user interface / user experience ideas $(p=.05)$, for example, "direct to consumer", "give discount on next purchase if sail is returned". Both methods had similar percentages of product feature-related ideas. Biomimicry's advantage in marketability was almost entirely due to generating more novelty than the other two methods ( $\mathrm{p}=8 \times 10-13)$, e.g. "structural color" or "helical flow exposes contaminants to wall". Whole System Mapping's lead in profitability ideas compared to the average of the other two design methods was almost entirely from cost reduction ideas $(\mathrm{p}=.02$; see examples above). Almost no ideas from any of the three design methods related to increasing revenue as opposed to reducing cost.

\section{LIMITATIONS}

Limitations include the number of design methods studied, the industries and demographics studied, data lost in unreadable Post-it notes, and the fact that not all ideas are good ideas. Three design methods are a tiny fraction of the hundreds in existence. This study had participants from multiple industries; different percentages of these industries might skew results. When results were subdivided by industry, sample sizes were too small to draw statistically significant conclusions. Larger sample sizes or testing only individual industries might find different results. This limitation applied to other demographics such as company size and type, or professionals versus students, as well. Participant demographics (ideas generated by job role, gender, or other) could have been measured using video tracking of individuals, but were not. The indecipherable ideas might have been decipherable if the workshops had been video-recorded to capture verbal discussions. Such videos might have also changed the coding of some Post-its. Finally, the study was short-term and only counted numbers of ideas in workshops; judging "good" or "bad" ideas was deemed too subjective, and would have required months of followup studies to determine how the ideas translated into final products or their market success. Such studies would, however, be valuable.

\section{CONCLUSIONS}

Which sustainable design methods are the best ones for the job at hand, or how could design methods be combined to maximize effectiveness? Rather than relying on theoretical analysis or the claims of design method creators, this paper investigated the question empirically, with preliminary results testing the different kinds of ideas resulting from three different design methods. Post-it notes of 1,115 design ideas from 29 workshops including over 30 companies were qualitatively coded for their different kinds of sustainability strategies and product innovations, then quantitatively analysed to count the percentage of ideas for each category. 
Results suggested that design teams highly prioritizing sustainability may find The Natural Step most valuable, those prioritizing innovation may find Biomimicry most valuable, and those desiring a balance of the two may find Whole System Mapping the most valuable. For sustainability strategies, if teams wish to improve materials and manufacturing, end of life, or social justice, The Natural Step may be best, especially for green material choice. To improve product durability, Biomimicry or Whole System Mapping may be best. All three design methods provided a reasonable percentage of energy-related ideas. None of the methods provided many ideas for transportation, to change user behaviour, for sharing / product service systems, or for life extension by repair / upgrade, so other design methods may be more useful for those topics.

If design teams aim to innovate through product quality, Biomimicry or Whole System Mapping may be best. Biomimicry provided more robustness ideas and Whole System Mapping provided more user experience ideas. For novel ideas, Biomimicry generated by far the highest percent. For profitability, Whole System Mapping generated the most ideas, primarily on cost-reduction. None of the methods provided many ideas for increasing revenue, so other design methods may be more useful for this.

Certainly, focusing ideation on these topics would change results for any design method. Whether the results would be useful or be like pounding nails with a screwdriver is unknown, and presumably context-dependent, requiring further research. But these results should aid design teams thinking critically about what design practices to use for their desired sustainability and innovation goals.

\section{REFERENCES}

Baumeister, D., Tocke, R., Dwyer, J., Ritter, S. and Benyus, J. (2013), "Biomimicry Resource Handbook: A Seed Bank of Best Practices", 2013 Edition, Biomimicry 3.8, Missoula, MT.

Baxter, K., Boisvert, A., Lindberg, C. and Mackrael, K. (2009), "Sustainability Primer: Step By Natural Step", The Natural Step Canada, available at: http://www.thenaturalstep.org/project/sustainability-primer-stepby- natural-step/ (accessed 21 July 2016).

Benyus, J.M. (1997), Biomimicry: Innovation Inspired By Nature, HarperCollins.

Brink, G., Destandau, N. and Hamlett, P. (2009), "Genealogy of the Living Principles", AIGA Center for Sustainable Design, available at: https://carlosfiorentino.files.wordpress.com/2010/03/aiga_the-livingprinciples.pdf.

Broman, G.I. and Robèrt, K.-H. (2017), “A framework for strategic sustainable development”, Journal of Cleaner Production, Vol. 140, pp. 17-31.

Christiaans, H.H.C.M. (2002), “Creativity as a Design Criterion”, Creativity Research Journal, Vol. 14 No. 1 , pp. 41-54.

Collado-Ruiz, D. and Ghorabi, H.O.-A. (2010), "Influence of environmental information on creativity", Design Studies, Vol. 31 No. 5, pp. 479-498.

Deutz, P., McGuire, M. and Neighbour, G. (2013), "Eco-design practice in the context of a structured design process: an interdisciplinary empirical study of UK manufacturers", Journal of Cleaner Production, Vol. 39, pp. 117-128.

Faludi, J. (2015), “A Sustainable Design Method Acting as an Innovation Tool”, ICoRD'15-Research into Design Across Boundaries Volume 2, Springer, pp. 201-212.

Faludi, J. (2017a), Golden Tools in Green Design: What Drives Sustainability, Innovation, and Value in Green Design Methods?, PhD Thesis, UC Berkeley.

Faludi, J. (2017b), "Recommending Sustainable Design Methods And Combinations By Characterizing Activities And Mindsets”, International Journal of Sustainable Design, Vol. 3 No. 2, pp. 100-136.

Faludi, J. and Agogino, A.M. (2018), "What Design Practices Do Professionals Use For Sustainability And Innovation?”, DS92: Proceedings of the DESIGN 2018 15th International Design Conference, Dubrovnik, Croatia, pp. 2633-2644.

Faludi, J. and Menter, A. (2013), "Product Design: Biomimicry", Autodesk Sustainability Workshop, May, available at: http://sustainabilityworkshop.autodesk.com/products/biomimicry (accessed 21 July 2016).

Häggman, A., Tsai, G., Elsen, C., Honda, T. and Yang, M.C. (2015), "Connections Between the Design Tool, Design Attributes, and User Preferences in Early Stage Design”, Journal of Mechanical Design, Vol. 137 No. 7, pp. 071408-071408.

Homans, G.C. (1949), “The strategy of industrial sociology”, American Journal of Sociology, Vol. 54 No. 4, pp. 330-337.

Keeley, L., Walters, H., Pikkel, R. and Quinn, B. (2013), Ten Types of Innovation: The Discipline of Building Breakthroughs, John Wiley and Sons. 
Knight, P. and Jenkins, J.O. (2009), “Adopting and applying eco-design techniques: a practitioners perspective”, Journal of Cleaner Production, Vol. 17 No. 5, pp. 549-558.

Oehlberg, L., Bayley, C., Hartman, C. and Agogino, A. (2012), "Mapping the Life Cycle Analysis and Sustainability Impact of Design for Environment Principles”, Leveraging Technology for a Sustainable World: Proceedings of the 19th CIRP Conference on Life Cycle Engineering, Springer, Berkeley, CA USA, pp. 221-226.

Oman, S.K., Tumer, I.Y., Wood, K. and Seepersad, C. (2013), “A comparison of creativity and innovation metrics and sample validation through in-class design projects", Research in Engineering Design, Vol. 24 No. 1, pp. 65-92.

Ramani, K., Ramanujan, D., Bernstein, W.Z., Zhao, F., Sutherland, J., Handwerker, C., Choi, J.-K., et al. (2010), “Integrated Sustainable Life Cycle Design: A Review”, Journal of Mechanical Design, Vol. 132 No. 9, p. 091004.

Robèrt, K.-H. (1991), "Educating A Nation: The Natural Step", In Context, Vol. 28, pp. 10-15.

Sarkar, P. and Chakrabarti, A. (2011), "Assessing design creativity”, Design Studies, Vol. 32 No. 4, pp. 348-383.

Shah, J.J., Smith, S.M. and Vargas-Hernandez, N. (2003), "Metrics for measuring ideation effectiveness", Design Studies, Vol. 24 No. 2, pp. 111-134.

Shah, J.J., Smith, S.M., Vargas-Hernandez, N., Gerkens, D.R. and Wulan, M. (2003), "Empirical studies of design ideation: Alignment of design experiments with lab experiments", ASME 2003 International Design Engineering Technical Conferences and Computers and Information in Engineering Conference, American Society of Mechanical Engineers, pp. 847-856.

Shedroff, N. (2009), Design Is the Problem: The Future of Design Must Be Sustainable, Rosenfeld Media, Brooklyn, NY USA.

Sheldrick, L. and Rahimifard, S. (2013), "Evolution in Ecodesign and Sustainable Design Methodologies", in Nee, A.Y.C., Song, B. and Ong, S.-K. (Eds.), Re-Engineering Manufacturing for Sustainability, Springer Singapore, pp. 35-40.

Telenko, C., O’Rourke, J.M., Conner Seepersad, C. and Webber, M.E. (2016), “A Compilation of Design for Environment Guidelines”, Journal of Mechanical Design, Vol. 138 No. 3, pp. 031102-031102-11.

Tromp, N. and Hekkert, P. (2016), "Assessing methods for effect-driven design: Evaluation of a social design method”, Design Studies, Vol. 43, pp. 24-47.

Vallet, F., Eynard, B., Millet, D., Mahut, S.G., Tyl, B. and Bertoluci, G. (2013), "Using eco-design tools: An overview of experts' practices”, Design Studies, Vol. 34 No. 3, pp. 345-377.

Vandevenne, D., Pieters, T. and Duflou, J.R. (2016), "Enhancing novelty with knowledge-based support for Biologically-Inspired Design”, Design Studies, Vol. 46, pp. 152-173.

White, P., Belletire, S. and Pierre, L.S. (2013), Okala Practitioner: Integrating Ecological Design, IDSA, Phoenix, AZ USA.

Yilmaz, S., Daly, S.R., Seifert, C.M. and Gonzalez, R. (2016), "Evidence-based design heuristics for idea generation", Design Studies, Vol. 46, pp. 95-124.

\section{ACKNOWLEDGMENTS}

This work was based on data from earlier research partially funded through US National Science Foundation Integrative Graduate Education and Research Traineeship grant \#1144885. 